\title{
SELECTION OF THICK COAL SEAM MINING METHOD USING ANAL YTIC HIERARCHY PROCESS
}

\section{Mustafa Emre Yetkin ${ }^{1}$ and Muharrem Kemal Özfirat ${ }^{2}$}

\author{
1, 2 Dokuz Eylul University Mining Engineering Department, Buca/ Izmir - Turkey.
}

Email: mustafa.yetkin@deu.edu.tr, kemal.ozfirat@deu.edu.tr

Received: Jul 16 th 2019

Accepted: Nov 01 ${ }^{\text {th }}, 2019$

Published: December 02 ${ }^{\text {th }}, 2019$

Copyright (C2016 by authors and Galileo Institute of Technology and Education of the Amazon (ITEGAM).

This work is licensed under the Creative Commons Attribution International License (CC BY 4.0).

https://creativecommons.org/licen ses/by/4.0/

\begin{abstract}
In thick coal seams, it is very important to select the correct mining method. Choosing a wrong method may be very costly to the company. All the factors affecting the mining method and the relations in between should be considered. When there are many factors under consideration, Analytic Hierarchy Process (AHP) is a very useful tool to analyze them. By use of AHP, errors that show up in conventional methods are minimized. In this study AHP is employed to select the mining method in a thick coal seam. The proposed approach starts with identifying the alternative mining methods that are applicable in thick coal seams. Then all the criteria affecting the mining method and the relations between them are defined by experts of the system. Finally AHP is used to find the method with the highest performance according to the selection criteria defined. Within this study the highest performance scores belong to Multi-slice retreatment longwall with filling (M4), Multi-slice retreatment longwall with caving (M3), Multi-slice advanced longwall with filling (M2) and Room and pillar (M9).
\end{abstract}

Keywords: Mining method selection, Analytic Hierarchy Process, Thick Coal Seam.

\section{INTRODUTION}

Since all the natural resources of Earth are scarce, it is of crucial importance to make the best use of mine reserves. Therefore, selecting the right mining method becomes a subject. When selecting the mining method in a mine, the goal is to choose the one which is most suitable in terms of technical, economical properties, national benefits and work safety. By this way, natural resources can be best used while the firm operates with maximum income. In addition, it may be very costly to change the mining method after starting operation.

Selection of mining method is the most important phase in planning an underground mine. In thick coal seams, there are quite a number of alternative mining methods and factors to select one of them. Among these selection criteria, production efficiency, seam properties, rock properties, ore recovery, economy and work safety can be listed.

Each mining method has its own advantages and disadvantages in terms of the selection criteria. It is very hard, time consuming and prone to errors to consider all the alternative mining methods with all the criteria and make a good selection without the help of scientific methods. In this case, Analytic Hierarchy Process (AHP) is a powerful tool to consider the alternative methods, the selection criteria, their interrelations and analyze them to come to a decision.

In this study, AHP is employed to select the most suitable mining method for a thick coal seam. Nine alternative mining methods are identified. Total of 20 selection criteria under five main groups are defined. The best mining method according to these criteria is selected. Figure 1 gives the hierarchical structure of the problem under study used in AHP.

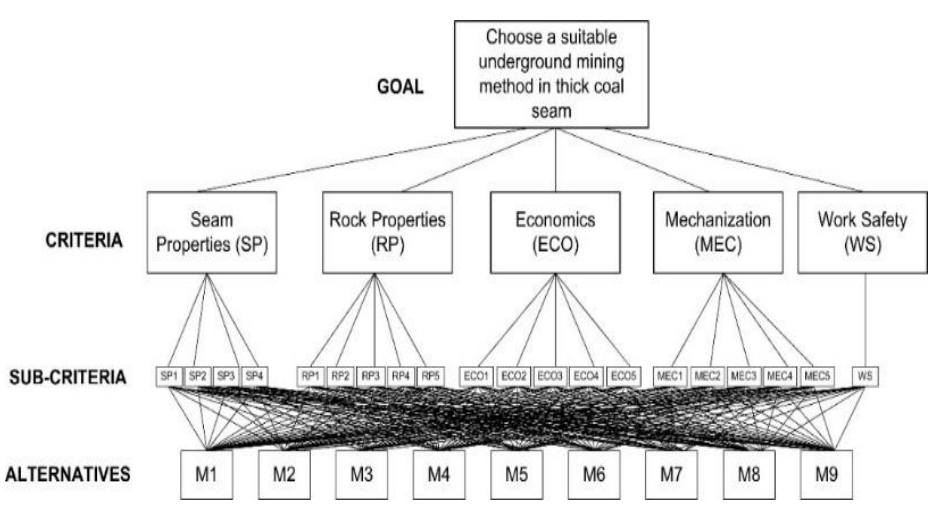

Figure 1: Hierarchical structure of the problem under study. Source: Authors, (2019). 
The rest of the paper is organized as follows. Section 2 gives a brief literature survey on the studies that have employed decision making tools in mining method selection. In Section 3, the proposed approach is explained in detail. Discussions and recommendations are given in Section 4. Finally, conclusion is given in Section 5.

\section{LITERATURE SURVEY}

In literature, there are a number of studies considering selection of mining methods or studies. A variety of decision making tools have been used in these studies. Proposed one of the first classification systems [1]. Suggested a selection chart for mining method selection [2]. Developed a selection chart based on the geometry of the deposit and the ground conditions of the ore zone for selecting mining method [3]. Proposed a numerical approach in method selection [4]. Modified the Nicholas' system and developed the UBC mining method selection process [5]. Used Yager's [6] method for selection of an optimum coal transportation system from pit to the power plant [7]. Used Yager's method and AHP method for mining method selection [8]. Used the AHP method for selection of open cast mining equipment [9]. Used two methods, an AHP based fuzzy multiple attribute decision-making method and fuzzy dominance method, to select the optimal mining method for Gol-Gohar iron mine in Iran [10]. Used AHP method and analyzed five different mining scenarios; drilling technology investment analysis, ground support design, tunneling systems design, shaft location selection and mine planning risk assessment [11]. Used the AHP method for the selection of a new alumina cement plant [12]. Used a hierarchical multi-dimensional objective system similar to AHP to select the more suitable mining method for the ELI and GLI coalfields in Turkey. Two mining methods compared on the basis of 19 criteria [13]. Developed a decision support system using AHP for the optimal environmental reclamation of an open-pit mine [14]. Applied AHP to select the best location for a concrete plant [15]. Used AHP to select site for limestone quarry expansion in Barbados [16]. Employed Yager's method and AHP to determine the optimum plant location for a new natural stone factory [17]. Used AHP based fuzzy multiple attribute decision-making methodology to select the most suitable underground mining method for the Ciftalan Lignite Mine in Turkey. Five possible mining methods were compared on the basis of 18 criteria [18]. Analytical Hierarchy Process is used to compare mechanized mining methods and conventional mining methods in the South African platinum mining industry [19]. Employed multicriterion optimization methods to select an optimal underground chromite mining technique [20]. Emloyed Fuzzy Analytic Hierarchy Process with TOPSIS to select the optimum mining method [21]. Proposed a methodology for group decisionmaking using AHP with cluster analysis for coal mine safety management in China [22].

\section{PROPOSED APPROACH}

Identifying the Alternative Mining Methods for a Thick Coal Seam

Coal seams which cannot be produced at once economically and technically can be called thick coal seams. With the developing technology today, seams thicker than $6 \mathrm{~m}$ are called thick coal seams. In this study, Mining methods that are applicable in thick coal seams are considered. These methods can be classified into three as multi-slice longwall (MSL) methods, longwall top coal caving (LTCC) methods and room-and pillar method. (Analysis is made according to the assumption that pillars are recovered.) In addition the mining methods are distinguished according to advanced or retreatment longwalls and caving and filling characteristics. In this manner nine mining methods are identified for thick coal seams. The list and schematic representations of the methods are given in Figure 2.

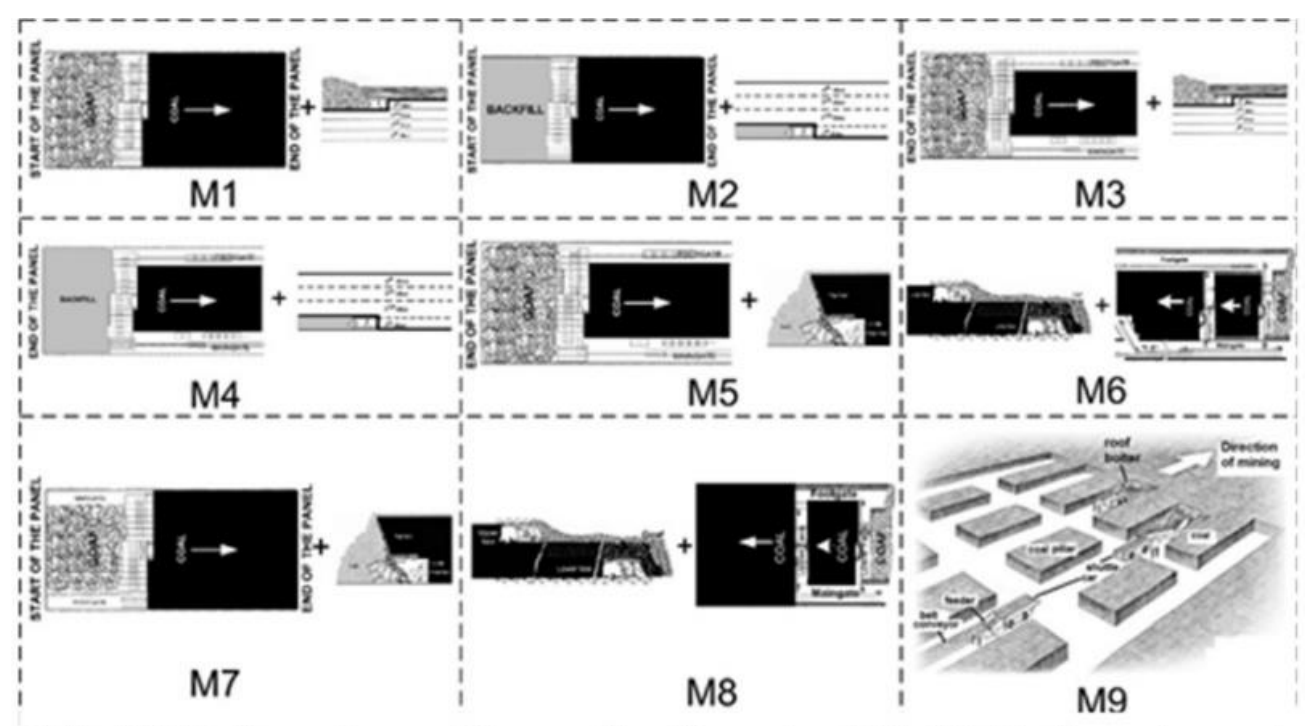

M1: Multi-slice advanced longwall with caving M2: Multi-slice advanced longwall with filling M3: Multi-slice retreatment longwall with caving M4: Multi-slice retreatment longwall with filling M5: Retreatment longwall top coal caving from bottom face M6: Retreatment longwall top coal caving from upper-lower face M7: Advanced longwall top coal caving from bottom face M8: Advanced longwall top coal caving from upper-lower face M9: Room-and Pillar method (Pillar is recovered)

Figure 2: Alternative Mining Methods in Thick Coal Seams Defining the Selection Criteria 
Source: Authors, (2019).

The second step in AHP is to define the selection criteria. In other words, the second step is to define the factors that the selection of mining method will depend on. In this study five main groups of factors are defined. These are Seam Properties (SP), Rock Properties (RP), Economy (ECO), Mechanization (MEC) and Work Safety (WS). Total of 20 selection criteria are defined under these five groups. The list of the criteria is given in Table 1.

Table 1: Main Group Factors and Sub-criteria.

\begin{tabular}{|c|c|}
\hline Variable code & Criteria \\
\hline \multicolumn{2}{|r|}{ Seam Properties } \\
\hline SP1 & Thickness of seam \\
\hline SP2 & Dip of seam \\
\hline SP3 & Coal combustion characteristic/Methane emission \\
\hline SP4 & Condition of dirt band \\
\hline \multicolumn{2}{|r|}{ Rock Properties } \\
\hline RP1 & Compressive strength of cosl \\
\hline $\mathrm{RP} 2$ & Compressive strength of hanging wall \\
\hline RP3 & Compressive strength of footwall \\
\hline RP4 & Mine depth \\
\hline RP5 & Subsidence \\
\hline \multicolumn{2}{|r|}{ Economics } \\
\hline $\mathrm{ECOl}$ & Cost and Productivity \\
\hline $\mathrm{ECO} 2$ & Dilution/Coal loss \\
\hline $\mathrm{ECO3}$ & Reserve \\
\hline $\mathrm{ECO} 4$ & Investment amount \\
\hline $\mathrm{ECO5}$ & Production amount \\
\hline \multicolumn{2}{|r|}{ Mechanization } \\
\hline MEC1 & Adaptation to mechanization \\
\hline MEC2 & Aquifer condition \\
\hline MEC3 & Qualified manpower \\
\hline MEC4 & Selective mining \\
\hline MEC5 & Easiness of work organization \\
\hline \multicolumn{2}{|r|}{ Work safety } \\
\hline WS & Work safety \\
\hline
\end{tabular}

Source: Authors, (2019).

Generating the Pairwise Comparisons.

In the third step, pairwise comparisons are generated by experts of the system. At this step, first the pairwise comparisons of the main groups are made. Then, pairwise comparisons of subcriteria within each main group are generated. Pairwise comparisons are made based on a scale of five. Afterwards, the analysis is made by Expert Choice software [23] to give the weights of each criteria and the inconsistency values of comparison matrices.

The comparison matrix of the main groups can be seen in Table 2 below. Since these matrices are symmetric according to the diagonal, only half of the matrix is filled. When the matrix is examined, it can be seen that work safety (WS) and seam properties (SP) are of equal important for the selection of mining method. In addition, seam properties (SP) is strongly more important than rock properties (RP), more important than economics (ECO) and absolutely more important than mechanization (MEC). Similarly, all other comparison values can be seen in Table 2 .

Table 2: The comparison of main group factors

\begin{tabular}{|c|c|c|c|c|c|}
\hline & SP & RM & ECO & MEC & WS \\
\hline SP & 1 & 3 & 2 & 5 & 1 \\
\hline RM & & 1 & 0.5 & 3 & 0.5 \\
\hline ECO & & & 1 & 2 & 0.5 \\
\hline MEC & & & & 1 & 0.2 \\
\hline WS & & & & & 1 \\
\hline
\end{tabular}

Source: Authors, (2019).

The comparisons are made by expert of the system. But still, there may exist inconsistencies. Therefore the pairwise comparison matrices should be checked for inconsistencies. The inconsistency ratio of the main group comparison matrix (Table 2) is found to be 0.05 by Expert Choice software. As long as this ratio does not exceed 0.1 , the matrix is accepted to be valid. In addition, the weights of the main groups are also computed by Expert Choice. The weight coefficients and the inconsistency value can be seen in the software output in Figure 3.

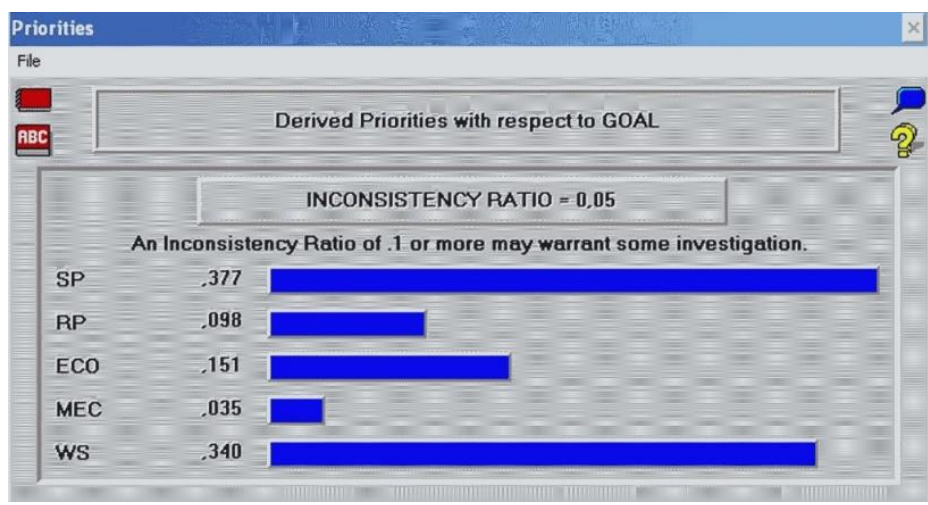

Figure 3: Expert Choice output, analysis of main groups. Source: Authors, (2019).

After handling main groups comes the subcriteria comparisons. The pairwise comparison matrices of seam properties, rock properties, economics, and mechanization can be seen in Figure 4 respectively. Since there are no subcriteria for work safety, there exists no comparison matrix for it. From Figure 4 , it can easily be understood that the most important factor is thickness of seam (SP1) among the four factors defined. Similarly, in rock properties group, compressive strength of hanging wall (RP2) is determined to be the most important factor. In the economics group factors, amount of reserve (ECO3) is the most important factor. Finally, adaptation to mechanization (MEC1) is set to be the most important criteria in mechanization group.

\begin{tabular}{|c|c|c|c|c|}
\hline \multicolumn{5}{|c|}{ The comparison of Seam Properties } \\
\hline \hline & SP1 & SP2 & SP3 & SP4 \\
\hline SP1 & 1 & 3 & 4 & 5 \\
\hline SP2 & & 1 & 3 & 5 \\
\hline SP3 & & & 1 & 2 \\
\hline SP4 & & & & 1 \\
\hline
\end{tabular}
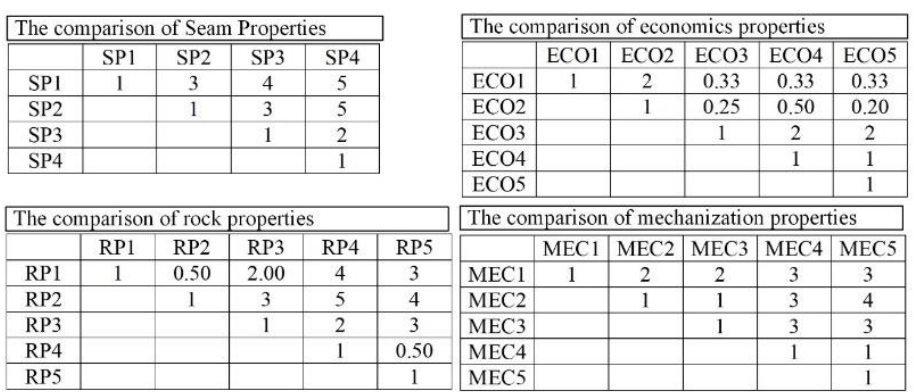

Figure 4: The comparison matrix of criterias. Source: Authors, (2019). 
The analysis of these comparison matrices are made and the outputs are given in Figure 5 below. As seen from Figure 5, the inconsistency ratios of all four matrices are less than 0,1 which leads us to the result that all matrices are valid. In addition, the weights of each criterion can be seen in the figure. However, these weights are the values within the group.
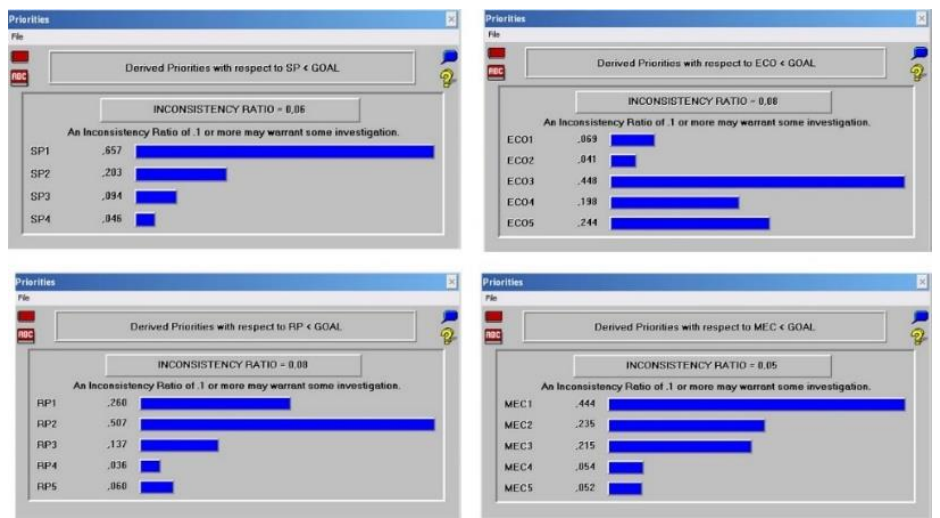

Figure 5: Expert Choice outputs, analysis of sub-criteria within each group.

Source: Authors, (2019).

Computation of Weights and Inconsistency Check

In this step, the overall weight of all criteria is computed as well as the overall inconsistency ratio. The Expert Choice output displaying the overall inconsistency ratio can be seen in Figure 5. The overall inconsistency ratio turns out to be 0.06 . That is the model built by AHP is consistent and valid. The weights of all criteria in the end of the overall analysis are given in Table 3.

Table 3: Final weights of selection criteria.

\begin{tabular}{|c|c|}
\hline Selection Criteria & Importance Ranking from AHP \\
\hline SP1 & 0.222 \\
\hline SP2 & 0.068 \\
\hline SP3 & 0.032 \\
\hline SP4 & 0.015 \\
\hline RM1 & 0.030 \\
\hline RM2 & 0.058 \\
\hline RM3 & 0.016 \\
\hline RM4 & 0.004 \\
\hline RM5 & 0.007 \\
\hline ECO1 & 0.014 \\
\hline $\mathrm{ECO} 2$ & 0.008 \\
\hline $\mathrm{ECO} 3$ & 0.089 \\
\hline ECO4 & 0.039 \\
\hline ECO5 & 0.048 \\
\hline MEC1 & 0.021 \\
\hline MEC2 & 0.011 \\
\hline MEC3 & 0.010 \\
\hline MEC4 & 0.002 \\
\hline MEC5 & 0.002 \\
\hline WS & 0.304 \\
\hline
\end{tabular}

Source: Authors, (2019).

Selecting the Best Method.

After finding the weights of the selection criteria, overall performance of each mining method should be computed. In order to do so, each alternative mining method is given a performance score in terms of each criterion. All the performance scores of methods can be seen in Table 4. The scores are given over 10. That is, for example, multi-slice advanced longwall with caving (M1) takes 5 over 10 in terms of work safety (WS). The values in the table can be interpreted in the same manner.

Table 4: Performance scores of mining methods in terms of each criteria (over 10).

\begin{tabular}{|c|c|c|c|c|c|c|c|c|c|c|}
\hline & \multicolumn{9}{|c|}{ Alternative Mining Methods } \\
\hline & & M1 & M2 & M3 & M4 & M5 & M6 & M7 & M8 & M9 \\
\hline \multirow{20}{*}{ 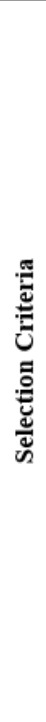 } & SP1 & 7 & 7 & 9 & 10 & 6 & 6 & 4 & 4 & 7 \\
\hline & SP2 & 5 & 7 & 6 & 9 & 7 & 7 & 5 & 5 & 4 \\
\hline & SP3 & 6 & 8 & 7 & 10 & 6 & 5 & 5 & 4 & 7 \\
\hline & SP4 & 7 & 7 & 9 & 8 & 7 & 7 & 7 & 7 & 9 \\
\hline & RM1 & 6 & 7 & 7 & 9 & 6 & 5 & 5 & 5 & 7 \\
\hline & RM2 & 6 & 8 & 7 & 10 & 5 & 6 & 4 & 5 & 7 \\
\hline & RM3 & 6 & 8 & 7 & 10 & 5 & 6 & 4 & 5 & 7 \\
\hline & RM4 & 7 & 8 & 7 & 10 & 7 & 7 & 7 & 7 & 7 \\
\hline & RM5 & 6 & 9 & 7 & 10 & 5 & 5 & 4 & 4 & 3 \\
\hline & ECO1 & 6 & 8 & 7 & 10 & 5 & 6 & 4 & 5 & 8 \\
\hline & $\mathrm{ECO} 2$ & 7 & 9 & 8 & 10 & 5 & 6 & 4 & 5 & 6 \\
\hline & $\mathrm{ECO3}$ & 8 & 9 & 8 & 10 & 4 & 5 & 4 & 5 & 7 \\
\hline & ECO4 & 6 & 5 & 6 & 5 & 9 & 7 & 9 & 7 & 8 \\
\hline & ECO5 & 10 & 8 & 10 & 8 & 7 & 8 & 7 & 8 & 7 \\
\hline & MEC1 & 6 & 6 & 10 & 7 & 9 & 9 & 8 & 8 & 9 \\
\hline & MEC2 & 8 & 8 & 8 & 8 & 9 & 8 & 9 & 8 & 8 \\
\hline & MEC3 & 7 & 8 & 7 & 9 & 6 & 6 & 5 & 5 & 6 \\
\hline & MEC4 & 7 & 9 & 7 & 9 & 4 & 4 & 4 & 4 & 8 \\
\hline & MEC5 & 3 & 5 & 4 & 5 & 9 & 8 & 8 & 7 & 8 \\
\hline & WS & 5 & 7 & 6 & 8 & 5 & 4 & 3 & 4 & 7 \\
\hline
\end{tabular}

Source: Authors, (2019).

The last step is to compute the overall scores of each alternative mining method. This is computed by taking the weighted average of performance scores. The weights are as given in Table 3. Overall score of multi-slice advanced longwall with caving (M1) is found to be 6.275 as given in Equation 1.

$$
\text { OverallScore }_{\mathrm{M} 1}=\mathrm{P}_{\mathrm{M} 1} * \mathrm{~W}
$$

where,

W: Weight matrix of selection criteria (from Table 3).

PM1: Performance matrix of method M1 (from Table 4).

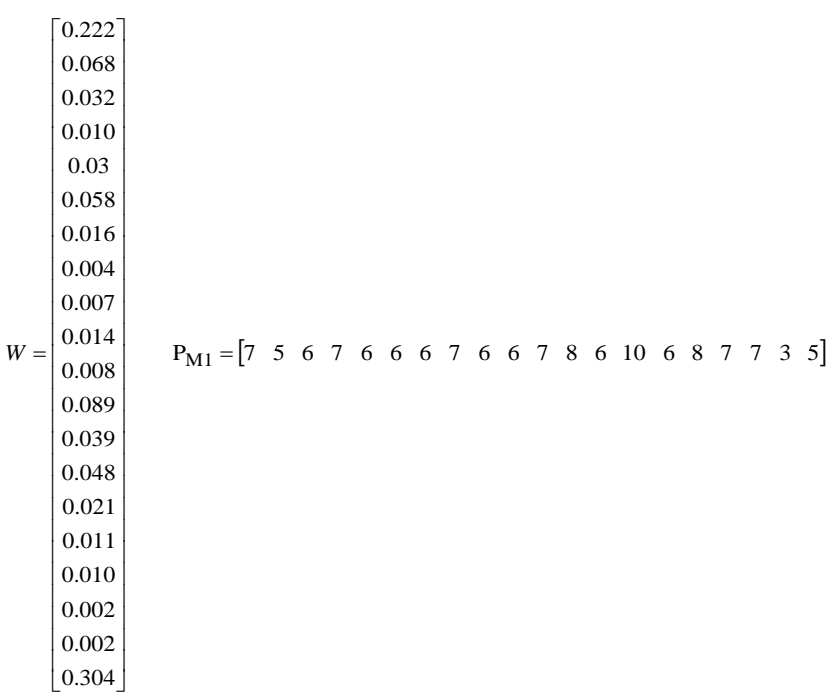

The overall scores of all alternative methods are listed in Table 5. As seen from the table, method M4 (multi-slice retreatment longwall with filling) turned out to be the best method 
according to these criteria. In addition, methods M3 and M2 (multislice retreatment longwall with caving and multi-slice advanced longwall with filling) obtain the second and third highest performance scores. According to this analysis, multi-slice retreatment longwall with filling is the most suitable mining method and can be selected for thick coal seam mining.

Table 5: Overall scores of alternative mining methods.

\begin{tabular}{|c|c|}
\hline $\begin{array}{c}\text { Mining } \\
\text { Method }\end{array}$ & $\begin{array}{c}\text { Overall } \\
\text { Performance }\end{array}$ \\
\hline M1 & 6.275 \\
\hline M2 & 7.302 \\
\hline M3 & 7.372 \\
\hline M4 & 8.866 \\
\hline M5 & 5.765 \\
\hline M6 & 5.541 \\
\hline M7 & 4.379 \\
\hline M8 & 4.793 \\
\hline M9 & 6.890 \\
\hline
\end{tabular}

Source: Authors, (2019).

\section{DISCUSSION AND RECOMMENDATIONS}

In this study, 20 criteria are grouped under five main groups. Firstly, main groups criteria are evaluated and then their effects on the methods are analyzed and finally mining method selection is made according to the AHP approach. Making the evaluations of all these criteria and alternative methods is both vey hard and prone to errors. Therefore AHP method, which is a powerful tool for multi-criteria decision making problems, is used to evaluate all 20 criteria and 9 mining methods to come to a decision in mining method selection.

As a result of evaluations, seam properties (SP) and work safety (WS) are the most important criteria. SP is certainly important in terms of economical and technical reasons. Work safety is much more important compared to other metalic mines due to gas, dust problems and collapse probabaility.

Results of AHP approach leads to the decision of mining method selection. But, it should be noted that mine conditions are different in every formation. Hence, mine conditions and engineering experiences should not be ignored when the approach developed in this study is used for another mine.

\section{CONCLUSIONS}

In this study, mining method selection is made in thick coal seam mining using AHP method. In contrary to, convetional approaches, AHP method is rapid, reliable and do not require much data. AHP method will contribute to the company in terms of efficiency. In order to obtain a reliable conclusion, all criteria should be evaluated realistically. This can be easily done by experts of the system as in this study.

According to the results of AHP method in this study, the highest performance scores belong to Multi-slice retreatment longwall with filling (M4), Multi-slice retreatment longwall with caving (M3), Multi-slice advanced longwall with filling (M2), Room and pillar (M9). Therefore, these methods are advised to be considered at the first planning of the thick coal seam mines. In addition, M4 method is better than other methods according to work safety and economy. Results of this study, are assessed as suitable in terms of mining techniques and economics. AHP method is used in decision mechanisms in mining in a successful way.

\section{REFERENCES}

[1] Boshkov, S.H., Wright, F.D. (1973). Basic and parametric criteria in the selection, design and development of underground mining systems. SME Mining Engineering Handbook. SMEAIME, New York.

[2] Morrison, R.G.K. (1976). AW Philosophy of Ground Control. McGill University, Montreal, Canada.

[3] Hartman, H.L. (1987). Introductory Mining Engineering. John Wiley, New Jersey.

[4] Nicholas D.E. (1993). Selection Procedure. Mining Engineering Handbook. Hartman, H.L. (ed.) SME. New York, pp. 2090-2105.

[5] Miller-Tait, L., Panalkis, R., Poulin, R. (1995). UBC mining method selection. In: Proceeding of the Mine Planning and Equipment Selection Symposium, pp. 163-168. Singhal R.K., Mehrotra A.K., Hadjigeorgiou J., Poulin R, (eds.).

[6] Yager, R.R. (1978). Fuzzy decision making including unequal objectives. Fuzzy Set Syst. Vol. 1, pp. 87-95.

[7] Bascetin, A., Kesimal, A. (1999). The study of a fuzzy set theory for the selection of an optimum coal transportation system from pit to the power plant. Int. J. Surf. Min. Reclam. Environ.Vol. 13, pp. 97-101.

[8] Karadogan, A. Bascetin, A., Kahriman, A., Gorgun, S. A. (2001). New approach in selection of underground mining method. In: Proceeding of the International Conference-Modern Management of Mine Producing, Geology and Environment Protection, pp. 171-183.

[9] Samanta, B. Sarkar, B., Mukherjee, S. (2002). Selection of opencast mining equipment by a multi-criteria decision-making process. Transaction Institution of Mining and Metallurgy. Vol. 111, pp. A136-A142.

[10] Bitarafan, M., Ataei, M. (2004). Mining method selection by multiple criteria decision making tools. The Journal of The Southern African Institute of Mining and Metallurgy. Vol. 104, pp. 493-498.

[11] Kazakidis, V.N. Mayer, Z., Scoble, M.J. (2004). Decision making using the analytic hierarchy process in mining engineering. Trans. Inst. Min. Metall. A. Vol. 113, pp. A30-A42.

[12] Ataei, M. (2005). Multicriteria selection for alumina-cement plant location in East-Azerbaijan province of Iran. J. S. Afr. Inst. Min. Metall. Vol. 105, pp. 507-514.

[13] Uysal, O., Demirci, A. (2006). Shortwall stopping versus sublevel longwall caving-retreat in ELI coal Fields, The Journal of the Southern African Institute of Mining and Metallurgy. Vol. 106, pp. 425-432. 
[14] Bascetin, A. (2007). Decision support system using analytical hierarchy process (AHP) for the optimal environmental reclamation of an open-pit mine. Environmental Geology. Vol. 52, pp. 663-672.

[15] Tezcan, O. (2007). AHP method and Application of ReadyMixed Concrete Plant in Land Selection, Ready-Mixed Concrete Journal, November-December. pp. 58-62 (in Turkish).

[16] Kumar, P., Ramcharan, K. (2008). Analytic hierarchy process helps select site for limestone quarry expansion in Barbados. Journal of Environmental Management. Vol. 88, pp. 1384-1395.

[17] Yavuz, M. (2008). Selection of plant location in the natural stone industryusing the fuzzy multiple attribute decision making method. The Journal of The Southern African Institute of Mining and Metallurgy. Vol. 108, pp. 641-649.

[18] Karadogan, A. Kahriman, A., Ozer, U. (2008). Application of fuzzy set theory in the selection of underground mining method, The Journal of the Southern African Institute of Mining and Metallurgy. Vol. 108, pp. 73-79.

[19] Musingwini, C., Minnitt, R.C.A. (2008). Ranking the efficiency of selected platinum mining methods using the analytic hierarchy process (AHP), Third International Platinum Conference 'Platinum in Transformation', The Southern African Institute of Mining and Metallurgy.

[20] Yavuz, M., Alpay, S. (2009). Underground Mining Technique Selection by Multicriterion Optimization Methods. Journal of Mining Science, Vol. 44, pp. 391-401.

[21] Mikaeil, R. Masoud Z. N. Ataei, M., Khalokakaie, R. A. (2009). decision support system using fuzzy analytical hierarchy process (FAHP) and TOPSIS approaches for selection of the optimum underground Mining method, Arch. Min. Sci. Vol. 54, pp. 349-368.

[22] Song, Y., Hu, Y. (2009). Group Decision-Making Method in the Field of Coal Mine Safety Management Based on AHP with Clustering. Proceedings of the 6th International ISCRAM Conference - Gothenburg, Sweden. Landgren J.and . Jul S, (eds.).

[23] Expert Choice Professional: Decision Support Software Publisher: Expert Choice, Inc., 4922 Ellsworth Avenue, Pittsburgh, PA 14213. 